doi https://doi.org/10.31977/grirfi.v20i2.1472

Recebido: 28/10/2019 | Aprovado: 26/04/2020

Received: 10/28/2019 | Approved: 04/26/2020

\title{
BOM DIA TEETETO: POR UM PENSAMENTO IMANENTE
}

\author{
José Rogério Vitkowski ${ }^{1}$ \\ Universidade Estadual de Ponta Grossa (UEPG) \\ (iD) https://orcid.org/0000-0002-4821-9576 \\ Email: jrvitkowski@gmail.com
}

\section{RESUMO:}

Esse artigo, de natureza filosófica, tem como objeto de estudo a crítica do modelo de pensamento representacional e dogmático efetivada pelo filósofo Gilles Deleuze. A pesquisa bibliográfica tem como horizonte teórico a filosofia da diferença, com foco no legado deleuziano. $O$ autor apresenta pressupostos que constituem o pensamento representacional na forma de postulados. São oito postulados, a saber: o da Cogitatio Universalis ("pensar naturalmente"), o ideal do senso comum, o modelo da recognição, o elemento da representação, o negativo do erro, o privilégio da designação, a modalidade das soluções e o resultado do saber. Cabe aqui apontar contornos desses postulados que evidenciam a imagem dogmática do pensamento - imagem traidora do que significa pensar. Essa imagem modelar possui fortes ressonâncias no universo educacional contemporâneo. Trata-se, portanto, de efetivar, em sintonia com Deleuze, uma crítica às imagens dogmáticas do pensamento e de seus limites que frequentemente despotencializam o pensar, o pensar a educação e, por extensão, a própria vida.

PALAVRAS-CHAVE: Filosofia da educação; Filosofia da diferença; Formação docente.

\section{GOOD MORNING TEETETO: FOR AN IMMANENT THINKING}

\begin{abstract}
:
This article, of a philosophical nature, has as its object of study a critique of the representative and dogmatic model of thought made by the philosopher Gilles Deleuze. A bibliographic research has as theoretical horizon the philosophy of difference, focusing on the Deleuzian legacy. The author presents assumptions that created representative thinking in the form of postulates. There are eight postulates: Cogitatio Universalis (thinking naturally, the ideal of common sense, the model of recognition, the element of representation, the negative of error, the privilege of design, one of the solutions and the result saber. It is worth pointing out the contours of these postulates that show a dogmatic image of thought - a traitorous image of what it means to think. This model image has strong resonances in the contemporary educational universe. It is therefore a matter of effecting, in tune with Deleuze, a critique of the dogmatic images of thought and its boundaries that often deemphasize thought, the thought of education, and, by extension, life itself.
\end{abstract}

KEYWORDS: Philosophy of education; Philosophy of difference; Teacher training.

\footnotetext{
${ }^{1}$ Doutor pela Universidade Federal de Santa Catarina (UFSC), Florianópolis - SC, Brasil. Professor da Universidade Estadual de Ponta Grossa, (UEPG), Ponta Grossa - PR, Brasil.
}

VITKOWSKI, José Rogério. Bom dia Teeteto: por um pensamento imanente. Griot : Revista de Filosofia, Amargosa - BA, v.20, n.2, p.30-38, junho, 2020 . 


\section{Introdução}

É de domínio comum afirmar que o grande tema do filósofo Gilles Deleuze é o pensamento. A vasta obra do filósofo francês, também efetivada em parceria com Félix Guattari, compreende um esforço de crítica a um tipo de pensamento designado de representação e entendido como constituição de uma filosofia da diferença ou da multiplicidade, ou do acontecimento (ALLIEZ, 1996).

Para evidenciar alguns marcos de referência desse percurso, nos inspiramos nos trabalhos de Magalhães (2001), Vasconcellos (2005). Esclarecemos que por opção metodológica realizamos uma visita específica aos constructos teóricos deleuzianos expressos na obra "Diferença e Repetição" (2006).

Deleuze apresenta em Diferença e Repetição (DR) vários pressupostos que constituem o o pensamento representacional na forma de postulados, a saber: o da Cogitatio Universalis ("pensar naturalmente"), o ideal do senso comum, o modelo da recognição, o elemento da representação, o negativo do erro, o privilégio da designação, a modalidade das soluções e o resultado do saber. Cabe aqui apontar alguns contornos desses postulados que evidenciam uma imagem dogmática do pensamento - imagem traidora do que significa pensar. Trata-se, portanto, de efetivar em sintonia com Deleuze uma crítica às imagens dogmáticas do pensamento, e de seus limites, que frequentemente despotencializam o pensar, o pensar a educação e, por conseguinte, a própria vida.

\section{Bom dia Teeteto ${ }^{2}$}

Com efeito, tanto a crítica à representação quanto a construção de uma filosofia da diferença são duas faces de um mesmo movimento do pensamento e que, na obra deleuziana, se desdobra num universo teórico no qual importa arrancar a diferença de seu estado de maldição, ou, mais precisamente, nas palavras de Deleuze: "tirar a diferença de seu estado de maldição parece ser, pois, a tarefa da filosofia da diferença" (DELEUZE, 2006, p.57).

De fato, Deleuze reivindica a Diferença como potência primeira (não metafísica, não derivada) e, no intuito de arrancá-la da maldição, perpassa a tradição filosófica, analisando a submissão da diferença à identidade. Essa submissão se traduz numa fórmula bastante conhecida $A=A$. Essa fórmula funciona como um princípio, o princípio geral da identidade, que se efetua, se autolegitima no âmbito da representação. A representação deixa escapar o mundo afirmado da diferença e, de acordo com Deleuze (2006, p. 93), "a representação tem apenas um centro, uma perspectiva única e fugidia, portanto, uma falsa profundidade; ela mediatiza tudo, mas não mobiliza nem move nada". A representação guarda um centro único que recolhe e representa todos os outros como uma unidade de série que ordena, que organiza, uma vez por todas, os termos e suas relações.

Ocorre que a representação não é separável de uma lei que a torna possível, a saber: "a forma do conceito como forma de identidade que constitui ora o em-si do representado (A é A), ora o para-si do representante $(\mathrm{Eu}=\mathrm{Eu})$. $\mathrm{O}$ prefixo $\mathrm{RE}$, na palavra representação, significa a forma conceitual do idêntico que subordina as diferenças (DELEUZE, 2006, p. 93).

A representação é assim o fundamento para conhecer tudo aquilo que é ou aparece presente, e que, dessa forma, remete a uma presença primeira. É este presente que deve ser 
representado, identificado, reconhecido. Eis, portanto, o desafio a ser enfrentado pela diferença: o universo da representação. A representação é, para Deleuze, o lugar da ilusão transcendental. E essa ilusão tem várias formas interpenetradas. Uma delas se refere ao pensamento, que se descobre com uma "imagem" composta de postulados que desnaturam seu exercício e sua gênese.

Cabe, assim, fazer uma crítica aos postulados do pensamento que compõem pressupostos da imagem pré-filosófica, ortodoxa, dogmática e moral do pensamento, na filosofia. Deleuze aborda, em DR, oito postulados. Cabe aqui algumas indicações gerais, tendo como intento evidenciar a imagem dogmática do pensamento. Essa imagem é limitante e trai profundamente o que significa pensar.

No primeiro postulado da "imagem do pensamento" - o princípio da "cogitatio natura universalis" - Deleuze versa sobre o pressuposto de que haveria, no ser humano, uma boa vontade para o pensar e uma natureza reta do pensamento:

É porque todo mundo pensa naturalmente que se presume que todo mundo saiba implicitamente o que quer dizer pensar. A forma mais geral da representação está, pois, no elemento de um senso comum como natureza reta e boa vontade. (Eudóxio e ortodoxia) (DELEUZE, 2006, p. 192).

É inútil, de acordo com Deleuze, multiplicar as declarações de filósofos, desde que "todo mundo tem, por natureza, o desejo de conhecer"; até "o bom senso é a coisa do mundo melhor repartida", para verificar a existência do pressuposto. O fato é que esses postulados existem e funcionam como pressupostos implícitos numa imagem de pensamento pré-filosófica e natural, tirada do elemento puro do senso comum. Segundo esta imagem, o pensamento está em afinidade com o verdadeiro, possui formalmente o verdadeiro e quer materialmente o verdadeiro. Ora, esta imagem do pensamento é problemática e subjaz com refinamentos e variantes em várias filosofias. Deleuze denomina essa imagem como dogmática ou ortodoxa, imagem moral.

Ao denominar o pressuposto de "imagem moral", Deleuze retoma Nietzsche, ao se interrogar sobre os pressupostos mais gerais da filosofia e pondera que "só a Moral é capaz de nos persuadir de que o pensamento tem uma boa natureza, o pensador, uma boa vontade, e só o Bem pode fundar a suposta afinidade do pensamento com o verdadeiro (DELEUZE, 2006, p. 193).

Para a realização de uma filosofia que evite esses postulados, Deleuze, propõe como ponto de partida uma crítica radical de qualquer imagem que o determine: "Como se o pensamento só pudesse começar, e sempre recomeçar, a pensar ao se libertar da imagem e dos postulados" (DELEUZE, 2006, p.193). Para Deleuze, seria necessário problematizar, então, aquilo que é universalmente aceito pela filosofia e que ela extrai de forma pura do senso comum: que todos pensam e sabem o que é pensar. Assim, ele considera necessária uma "má vontade" perante a aceitação de qualquer imagem pré-concebida, ou seja, seria necessária uma atitude de recusa face à participação nesse bom senso, para que a reversão dos pressupostos da "cogitatio natura universalis" se torne possível. Se não escaparmos dessa imagem do pensamento - que se tornou a imagem de direito para a filosofia - não poderemos propor nenhuma outra forma de pensar, conforme o pensador francês.

Na continuidade, Deleuze apresenta o segundo postulado do pensamento: o ideal do senso comum. Nesse postulado, é evocada a figura de Descartes e a afirmação segundo a qual o bom senso é a coisa do mundo melhor repartida. Esse gracejo, como afirma Deleuze, consiste em lembrar que os homens lamentam, a rigor, a falta de memória, de imaginação, dentre outros,

VITKOWSKI, José Rogério. Bom dia Teeteto: por um pensamento imanente. Griot : Revista de Filosofia, Amargosa - BA, v.20, n.2, p.30-38, junho, 2020 . 
mas se sentem sempre muito bem-dotados do ponto de vista da inteligência e do pensamento. Ora, essa afirmação permite erigir uma imagem do pensamento tal como ele é de direito: a boa natureza e a afinidade com o verdadeiro pertenceriam, de direito, ao pensamento, qualquer que fosse a dificuldade de traduzir o direito nos fatos ou de reencontrar o direito para além dos fatos. O bom senso ou o senso comum natural são, pois, tomados como a determinação do pensamento puro. Deleuze se contrapõe a essa imagem, e realiza então uma incursão sobre o modelo da recognição, objeto do terceiro postulado.

O modelo da recognição toma como ponto de partida o pressuposto de que "todos pensam". Deleuze define a recognição como "um exercício concordante de todas as faculdades sobre um objeto suposto como sendo o mesmo: é o mesmo objeto que pode ser visto, tocado, lembrado, imaginado, concebido" (DELEUZE, 2006, p.194). Assim, a recognição mantém um pensamento naturalmente reto; a essência da recognição é o modelo. Nesse sentido, a recognição conserva aquilo que é essencial como pressuposto: o modelo do bom, do belo, do verdadeiro, do importante, etc. e recorre a esses modelos para encontrar soluções para os problemas, tranquilizando o pensamento: com esse pressuposto, o pensamento "reconhece" o que é importante pensar, por que é importante pensar de que modo se deve pensar aquilo que é importante pensar e o que é necessário pensar para atingir o ideal do pensamento. A confluência das faculdades sobre um objeto traz em seu interior o "reconhecimento" como resultado da concordância entre elas, tendo em vista a identidade desse mesmo objeto. $E$, simultaneamente, a recognição exige:

O princípio subjetivo da colaboração das faculdades para "todo mundo", isto é, um senso comum como "concórdia facultatum"; e, para o filósofo, a forma de identidade do objeto exige um fundamento na unidade de um sujeito pensante no qual todas as outras faculdades devem ser modos (DELEUZE, 2006, p. 195).

Deleuze explica que esse é o sentido do "Cogito" Cartesiano como começo ${ }^{3}$. Ele exprime a unidade de todas as faculdades no sujeito e a possibilidade de todas as faculdades se referirem a uma forma de objeto que reflita a identidade subjetiva e "dá, assim, um conceito filosófico ao pressuposto do senso comum, ele é o senso comum tornado filosófico" (DELEUZE, 2006, p. 195).

Nesse contexto, o filósofo afirma que esse modelo é deplorável para a filosofia, pois não lhe permite romper com a doxa. Deleuze irá considerar que a evidencia e que os atos de recognição existem e ocupam grande parte de nossa vida cotidiana. Daqui emerge a célebre frase "É uma mesa, é uma maçã, é o pedaço de cera, bom-dia, Teeteto. Mas quem pode acreditar que o destino do pensamento se joga aí e que pensemos quando reconhecemos?" (DELEUZE, 2006, p.197). Além do mais, a recognição não se dá apenas no reconhecimento do objeto, mas também nos valores sobre o objeto. Daqui procede a outra inquietante afirmação: "se a recognição encontra sua finalidade prática nos "valores estabelecidos" temos a repetição do postulado da "Cogitatio natura", que, sob este modelo, dá testemunho de inquietante complacência.

Ao evocar Nietzsche, questionador das verdades que a ninguém embaraça, Deleuze dispara: "que é um pensamento que não faz mal a ninguém, nem àquele que pensa, nem aos outros? O signo da recognição celebra esponsais monstruosos em que o pensamento "reencontra" o Estado (DELEUZE, 2006, p. 198). Esse texto traz implicações interessantes para o exercício do pensamento por parte do filósofo.

Com a recognição têm-se um passo na direção do quarto postulado: "O elemento da representação". Para Deleuze, a representação não permite ao pensamento diferenciar-se de

${ }^{3} \mathrm{O}$ "Eu penso" é o princípio mais geral da representação! (DELEUZE, 2006, p. 201)

VITKOWSKI, José Rogério. Bom dia Teeteto: por um pensamento imanente. Griot : Revista de Filosofia, Amargosa - BA, v.20, n.2, p.30-38, junho, 2020 . 
seus pressupostos. Os elementos que dela fazem parte, a identidade no conceito, a oposição na determinação do conceito, a analogia do juízo, a semelhança no objeto. Cada elemento solicita uma faculdade, mas se estabelece também de uma faculdade a outra no seio de um senso comum. Um expressivo texto parece esclarecedor:

O Eu penso é o princípio mais geral da representação, isto é, a fonte destes elementos e a unidade de todas estas faculdades: eu concebo, eu julgo, eu imagino e me recordo, eu percebo - como os quatro ramos do Cogito. E, precisamente sobre estes ramos, é crucificada a diferença. Quádruplo cambão, em que só pode ser pensado como diferente o que é idêntico, semelhante, análogo e oposto; é sempre em relação a uma identidade concebida, a uma analogia julgada, a uma oposição imaginada, a uma similitude percebida que a diferença se torna objeto de representação (DELEUZE, 2006, p. 201).

Desse modo, o mundo da representação é impotente em pensar a diferença em si mesma, uma vez que pensa a diferença sempre em relação algo do qual o pensado se diferenciou. Além do mais, o problema da representação está em tratar a diferença como erro ou como falsa representação, temas do próximo postulado.

No quinto postulado: o "negativo" do erro, Deleuze, manifesta que a imagem dogmática do pensamento só reconhece o erro como desventura do pensamento e a ele tudo reduz. Nessa perspectiva, o erro é apenas o reverso de uma ortodoxia racional. $O$ erro testemunha em favor daquilo de que ele se desvia, em favor de uma retidão, de uma boa natureza e de uma boa vontade daquele que é dito enganar-se. "Portanto, o erro rende homenagem à verdade, na medida em que, não tendo forma, dá ao falso a forma do verdadeiro" (DELEUZE, 2006, p. 215).

$O$ erro é o "negativo" que se dá na imagem dogmática de pensamento e que aí incluí redutoramente (a besteira, a maldade e a loucura), consideradas como fatos de uma causalidade externa, reduzidas ao erro, e não como outros modos de pensar.

No sexto postulado, "o privilégio da designação", Deleuze problematiza a questão do sentido dos problemas. Cita, como exemplo, as polêmicas dos matemáticos, nas quais é a duvidoso que haja uma crítica entre os pares, por cometerem enganos em resultados ou cálculos; a crítica advém, antes de tudo, pela produção de um teorema insignificante, um problema destituído de sentido. O nó problemático é que o erro entra pela porta dos fundos, porque a filosofia atribui à proposição um valor de verdade, considerando-a como condição do verdadeiro. O sentido encontraria na recognição da própria proposição a sua verdade e também o seu erro. Desse modo

Remetendo o verdadeiro e o falso à relação de designação na proposição, dá-se um sexto postulado, da própria proposição ou da designação, que recolhe os precedentes e se encadeia com eles (a relação de designação é somente a forma lógica da recognição) (DELEUZE, 2006, p. 221).

O problema, se pensarmos a partir dessa imagem dogmática do pensamento, é sempre dado antecipadamente, e a resposta é uma busca entre as várias possibilidades de solução. Nesse modo de pensar, o agravante é que, uma vez dada a solução, o problema desaparece, perde sua força e sua função. O pensar seria, então, a busca de soluções para os problemas dados e seria apenas concernente às soluções e não à colocação dos problemas. Certamente aqui encontramos um vasto campo para a crítica das pedagogias apaziguadoras dos problemas. Não é raro encontrar nas narrativas pedagógicas a busca incessante por soluções imediatistas que não admitem a força do problema para pensar. 
Nesse itinerário, decorre o sétimo postulado: A modalidade das soluções. A enfaticidade com que Deleuze aborda esse tópico é notória e instigante:

Fazem-nos acreditar, ao mesmo tempo, que os problemas são dados já feitos e que eles desaparecem nas respostas ou na solução; sob este duplo aspecto, eles seriam, apenas quimeras. Fazem-nos acreditar que a atividade de pensar, e também o verdadeiro e o falso em relação a esta atividade, só começam com a procura de soluções, só concernem às soluções (DELEUZE, 2006, p. 228).

O problema dessa imagem dogmática está em não permitir que os próprios problemas sejam formulados como uma atividade do pensamento. Exemplos não faltam: o mestre que apresenta um problema para ser resolvido pelo aluno, e cujo resultado é qualificado de falso ou verdadeiro por uma autoridade poderosa; o convite para resolver problemas de outro lugar e que nos consola ou distrai, ou o problema como obstáculo a ser vencido. Essas e outras situações são encontradas no cotidiano educacional, basta lembrar os testes instrucionistas, avaliações governamentais de competências, os concursos, atividades avaliativas -seja na modalidade presencial ou a distância- que reproduzem uma imagem grotesca da cultura representacional.

Deleuze aponta para uma sutil escravidão enquanto não dispusermos dos próprios problemas, de uma participação nos problemas, de um direito aos problemas, de uma gestão dos problemas. Esse postulado é adensado, quando se considera a questão das respostas e soluções, segundo o qual o verdadeiro e o falso só começam com as soluções ou quando qualificam as respostas. Em vez de concernir às soluções, o verdadeiro e o falso afetam, em primeiro lugar, os problemas. $\mathrm{O}$ autor nos explica: Uma solução tem sempre a verdade que merece de acordo com o problema a que ela corresponde; e o problema tem sempre a solução que merece de acordo com sua própria verdade ou falsidade, isto é, de acordo com seu sentido" (DELEUZE, 2006, p. 229). Aqui está o significado das célebres frases: "os verdadeiros grandes problemas só são colocados quando são resolvidos" ou "a humanidade só se põe problemas que é capaz de resolver". O problema ou o sentido é o lugar de uma verdade originária e, ao mesmo tempo, a gênese de uma verdade derivada.

Nesse itinerário nocional, Deleuze discorre sobre a importância ontológica e epistemológica da categoria de problema e reafirma:

Um problema não existe fora de suas soluções. Mas, em vez de desaparecer, ele insiste e persiste nas soluções que o recobrem. Um problema se determina ao mesmo tempo em que é resolvido; mas sua determinação não se confunde com a solução: os dois elementos diferem por natureza, e a determinação é como a gênese da solução concomitante (DELEUZE, 2006, p. 235).

Para o filósofo há uma série de elementos cujas relações precisam ser pensadas enquanto elaboração de uma teoria geral do problema.

Na sequência da obra Diferença e Repetição temos o oitavo postulado: o resultado do saber. Ao leitor perceber as ressonâncias na educação. Nesse postulado, é desenvolvida a relação entre o "problema", o "saber" e o "aprender". A relação entre o problema e o aprender é diferente da relação que pode ser estabelecida entre o problema e o saber.

Na relação do problema (ideia) com o aprender, temos, de um lado, o aprendiz como aquele que constitui e enfrenta problemas práticos ou especulativos. Mas o que é aprender? Deleuze responde que "Aprender é o nome que convém aos atos subjetivos operados em face da objetividade do problema, ao passo que saber designa apenas a generalidade do conceito ou a calma posse de uma regra das soluções" (DELEUZE, 2006, p.237). Um exemplo expressivo

VITKOWSKI, José Rogério. Bom dia Teeteto: por um pensamento imanente. Griot : Revista de Filosofia, Amargosa - BA, v.20, n.2, p.30-38, junho, 2020 . 
advém de um experimento da psicologia, no qual um macaco deva encontrar o seu alimento, numa caixa com cor determinada, em meio a outras de diversas cores. Há, então, um período paradoxal, em que o número de "erros" diminui, sem que, todavia, o macaco possua o "saber" ou a "verdade" de uma solução para cada caso. Feliz momento, afirma Deleuze, "em que o macaco-filósofo se abre à verdade e produz o verdadeiro, mas somente na medida em que ele começa a penetrar na espessura colorida de um problema. $O$ texto desemboca numa definição da qual aprender é penetrar no universal das relações que constituem a ideia e nas singularidades que lhes correspondem. Deleuze destaca inda, que há um momento no aprender que está no limiar de consciência, e que, portanto, "aprender passa pelo inconsciente, passa-se sempre no inconsciente, estabelecendo, entre a natureza e o espírito, o liame de uma cumplicidade profunda" (DELEUZE, 2006, p. 237). Mas pode-se objetar novamente: afinal, o que significa aprender? Referindo-se ao aprendiz, Deleuze afirma que cada faculdade deve ser elevada a um exercício transcendente. $O$ aprendiz procura fazer que nasça na sensibilidade esta segunda potência que aprende o que só pode ser sentido. É esta a educação dos sentidos. É um exercício dinâmico de várias faculdades. Daqui decorre um célebre e interessante texto deleuziano:

A partir de que signos da sensibilidade, por meio de que tesouros da memória, sob quais torções determinadas pelas singularidades de que Ideia será o pensamento suscitado? Nunca se sabe de antemão como alguém vai aprender, que amores tornam alguém bom em latim, por meio de que encontros se é filósofo, em que dicionário se aprende a pensar. Os limites das faculdades se encaixam uns nos outros sob a forma partida daquilo que traz e transmite a diferença. Não há método para encontrar tesouros nem para aprender, mas um violento adestramento, uma cultura ou Paideia que percorre inteiramente o indivíduo (DELEUZE, 2006, p. 237).

O método, portanto, não garante o pensamento. É um meio de saber quem regula a colaboração de todas as faculdades. Tem um papel regulador. Mas também, emenda o autor, é manifestação de uma "cogitatio natura", pressupondo uma boa vontade assim como uma decisão premeditada do pensador. A cultura é o movimento de aprender, a aventura do involuntário, encandeando uma sensibilidade, uma memória, depois um pensamento. O Aprender, nesse contexto, é apenas o intermediário entre não-saber e saber, a passagem viva de um a outro. Pode-se dizer que aprender, afinal de contas, é uma tarefa infinita e a "aprendizagem recai, sobretudo, do lado do rato no labirinto, enquanto que o filósofo fora da caverna leva consigo apenas o resultado - o saber - para dele extrair os princípios transcendentais (DELEUZE, 2006, p. 238). Essas noções desestabilizam a procura incessante de quantificar o quanto se aprende. Aprender, portanto, tem muito mais a ver com o processo, do que com o ponto de chegada.

Esses são alguns aspectos que permitem fazer uma crítica aos postulados dogmáticos do pensamento, que encontram na "cogitatio natura", a sua auto justificação e legitimidade. Deleuze demonstra, portanto, a necessidade de superar essa imagem do pensamento, revertê-la, por um pensamento sem imagem. Trata-se de um pensamento que não dá as mãos à recognição, nem a filosofia da representação com suas marcas de universalidade conceitual, de uso correto da razão e de boa vontade do pensador, com as respectivas expressões. Assim, a filosofia deleuziana estabelece duas dimensões ou espaços, "o espaço da imagem do pensamento, que é dogmático, ortodoxo, metafísico, moral, racional, transcendente..., e o espaço do pensamento sem imagem, que é pluralista, heterodoxo, ontológico, ético, trágico, imanente". (MACHADO, 2010, p. 26).

Essa citação faz ter presente que é o pensamento sem imagem que viabiliza liberar a diferença das amarras e da domesticação do pensamento representacional, como já sugeriu belamente Foucault:

VITKOWSKI, José Rogério. Bom dia Teeteto: por um pensamento imanente. Griot : Revista de Filosofia, Amargosa - BA, v.20, n.2, p.30-38, junho, 2020 . 
Para libertar a diferença, precisamos de um pensamentos em contradição, sem dialética, sem negação: um pensamento que diga sim à divergência; um pensamento afirmativo, cujo instrumento seja a disjunção; um pensamento múltiplo, da multiplicidade dispersa e nômade que não limita nem reagrupa nenhuma das coações do mesmo; um pensamento que não obedece ao modelo escolar (que falsifica a resposta já feita) mas que se dirige a problemas insolúveis, quer dizer, a uma multiplicidade de pontos extraordinários que se descobre à medida que se distinguem as suas condições que insiste, subsiste, num jogo de repetições (FOUCAULT, 1997, p.68).

Esse pensamento sem imagem possui uma afinidade e um endereçamento. Deleuze, em consonância com Nietzsche, propugna que o pensamento tem afinidade direta com a vida, mas a vida imanente, que afirma a si mesma: um pensamento que conduza a vida até o fim daquilo que ela pode:

A vida seria a força ativa do pensamento e o pensamento o poder afirmador da vida. Pensar seria descobrir, inventar novas possibilidades de vida, a vida ultrapassando os limites que o conhecimento lhe fixa, o pensamento ultrapassando os limites que a vida lhe fixa. O pensador com uma bela afinidade entre pensamento e vida, instintos assentados em solos contrários que, relacionados, se impulsionam mutuamente para adiante. Essa afinidade entre pensamento e vida é também a essência da arte (DELEUZE, 1976, p. 48).

Eis, portanto, um grito contra toda forma de limitação imposta pela insipidez do racionalismo representacional e dogmático. Trata-se então de afirmar a vida por ela mesma por meio de encontros intensivos do pensamento. Na educação, trata-se de romper com as soluções simplificantes do senso comum, mas também romper com a pseudocientificidade que tudo quer medir, prever e controlar.

Neste sentido há um clarão reluzente que não pode ser ignorado. Em "A imanência uma Vida", afirma:

Dir-se-á que a pura imanência é UMA VIDA, nada mais. Ela não é imanência à vida, mas o imanente que não é imanente a nada específico é ele mesmo uma vida. Uma vida é a imanência da imanência, a imanência absoluta: ela é potência e beatitude completas (DELEUZE, 2002, p. 40).

Assim como a vida é imanente à própria Vida, e não pode ser separada, não pode ser dividida e nada pode haver fora dela. Uma vida está por todos os lugares, por todos os momentos que atravessam este ou aquele sujeito vivo e que medem tais objetos vividos: vida imanente trazendo os acontecimentos ou singularidades que apenas se atualizam nos sujeitos e nos objetos. Essa vida indefinida não tem, ela mesma, momentos, por mais próximos que estejam uns dos outros, mas apenas entretempos, entremomentos (DELEUZE, 2002, p. 41).

Pensar antidogmaticamente implica, portanto, não separar o pensamento da vida. Pensar e ser é uma coisa só. Pensar, já não mais à luz do tempo cronológico, mas à luz de Aiôn, um entretempo acontecimental, tempo indefinido do acontecimento. 


\section{Referências}

ALLIEZ, Éric. Deleuze Filosofia Virtual. Trad. Heloisa B.S. Rocha. São Paulo: Ed. 34, 1996. DELEUZE, Gilles. Diferença e repetição. 2ed. Trad. Luiz Orlandi e Roberto Machado. Rio de Janeiro: Graal, 2006.

DELEUZE, Gilles. A imanência: uma vida. Revista Ethica, Rio de Janeiro, v. 9, n. 1 e 2, p. 3943, 2002.

DELEUZE, Gilles. Nietzsche e a filosofia. Brasileira. Tradução de Ruth Joffily Dias e Edmundo Ferenandes. Rio de Janeiro: Editora Rio, 1976.

FOUCAULT, Michel. Nietzsche, Freud, Marx. Theatrum Philosoficum. São Paulo: Princípio, 1997.

MACHADO, Roberto. Deleuze, a arte e a filosofia. Rio de Janeiro: Zagar, 2010.

MAGALHÃES, Rui. Deleuze: a pluralidade metafísica. Sobre Gilles Deleuze, Diferença e Repetição. Lisboa: Relógio d'Água, 2001.

VASCONCELLOS, Jorge. A filosofia e seus intercessores: Deleuze e a não Filosofia. Educação e Sociedade, Campinas, vol. 26, n. 93, p. 1217-1227, Set./Dez. 2005. Disponível www.cedes.unicamp.br/publicacoes/edicao/123

Autor(a) para correspondência: José Rogério Vitkowskim, Praça Santos Andrade, 01 - Centro, 84010-330, Ponta Grossa-PR, Brasil. jrvitkowski@gmail.com 